\title{
Spontaneously induced prophages are abundant in a naturally evolved bacterial starter culture and deliver competitive advantage to the host
}

\author{
Svetlana Alexeeva*, Jesús Adrián Guerra Martínez, Maciej Spus and Eddy J. Smidº
}

\begin{abstract}
Background: In complex microbial ecosystems such as the marine environment, the gastrointestinal tract, but also in mixed culture fermentations, bacteriophages are frequently found to be a part of the microbial community. Moreover, prophages or prophage-like elements are frequently identified in sequenced bacterial genomes. The mixed undefined starter cultures represent an ecosystem which is shaped by long term evolution under relatively defined environmental conditions and provides an interesting model to study co-evolution of phages and their hosts as well as the impact of diversity on microbial community stability.

Results: In the present study we investigated the presence, identity and behaviour of prophages in lactococci being part of a complex cheese starter culture. Genome analysis of representative strains of the 7 genetic lineages of Lactococcus lactis constituting the culture indicated the presence of prophages in all strains. Exposure of potential lysogens to mitomycin C confirmed the release of $\sim 10^{10} \cdot \mathrm{ml}^{-1}$ phage particles from all tested strains. Furthermore, phages were also released in substantial amounts due to spontaneous induction: more than $10^{8} \cdot \mathrm{ml}^{-1}$ phage particles were present in cultures under non-inducing conditions. This observation suggests continuous release of phage particles by the lactococci. The released bacteriophages exhibited an unusual morphology. For most strains tested, tailless icosahedral phage heads were found. The competitive advantage of lysogens compared to their cured derivatives and their high abundance in the culture suggests that the released tailless bacteriophages play an important role in the ecosystem.
\end{abstract}

Conclusions: The results of this study indicate that chromosomal genetic elements are active participants in the stable complex microbial community of the starter culture. We show that prophages are abundant in such a community, are produced continuously in large amounts and, despite the huge metabolic burden imposed on the cells by phage particle production, provide a selective advantage to the host.

Keywords: Lactococcus lactis, Prophage, Bacteriophage, Lysogeny, Mixed culture, Evolution

\section{Background}

Artisanal starter cultures for the production of cheese have a long history of use in a dairy environment and can be considered as domesticated cultures [1]. For that reason, these cultures represent an interesting model ecosystem shaped by relatively defined environmental conditions. Such dairy cultures consist of undefined

\footnotetext{
* Correspondence: svetlana.alexeeva@yahoo.co.uk; eddy.smid@wur.nl Laboratory of Food Microbiology, Wageningen University, Wageningen, The
} Netherlands

(c) The Author(s). 2018 Open Access This article is distributed under the terms of the Creative Commons Attribution 4.0 International License (http://creativecommons.org/licenses/by/4.0/), which permits unrestricted use, distribution, and reproduction in any medium, provided you give appropriate credit to the original author(s) and the source, provide a link to the Creative Commons license, and indicate if changes were made. The Creative Commons Public Domain Dedication waiver (http://creativecommons.org/publicdomain/zero/1.0/) applies to the data made available in this article, unless otherwise stated. 
of these domesticated lactic acid bacteria uncovered high incidence of lysogeny [5-7]. This shows that prophages are rather common residents of lactic acid bacterial genomes. The prophages of $L$. lactis belong to the temperate P335 group of the Siphoviridae family, a taxon of the order of Caudovirales (tailed bacteriophages). They resemble lambdoid phages, are heterogeneous in nature and have genomes with a highly mosaic structure with functional modules exchangeable through homologous recombination [8-10]. Frequently, prophages identified from genomic sequences are considered defective or in a state of mutational decay [11]. Nevertheless the presence of prophages in dairy strains is commonly regarded as a threat because bacteriophages can cause significant bacterial mortality leading to production delays or even product loss [12]. Therefore, lysogenic strains rarely find their way to industrial processes [12], thus the beneficial side of lysogeny seems to be underestimated so far.

Whereas lytic bacteriophages can be regarded as predators of prokaryotes, prophages are considered to have either a parasitic or mutualistic interaction with the host [13]. Prophages may carry beneficial properties encoded in their genomes providing the lysogens a selective advantage over their non-lysogenic counterparts [7, 14-16]. A positive impact of prophages on population fitness has recently been addressed by Bondy-Denomy and Davidson [17]. Such benefits are, for example, super-infection immunity, superinfection-exclusion, or adaptive genes of immediate usefulness, acquired from previous hosts. Prophages can potentially spread such properties within a population, shaping a microbial community $[18,19]$. In this respect, complex dairy starter cultures provide an interesting model to study co-evolution of phages and their hosts in the dairy environment.

Recently, the originally undefined mixed starter culture Ur has been characterized in detail [2]. Sequencing of representative strains originating from the Ur culture revealed a considerable part of the genomes is made up of prophage-like elements. In this study we addressed the question if these phage-related genetic elements are active participants in the stable complex microbial community, for instance by triggering fully functional prophages into a replicative, lytic life cycle.

\section{Methods}

\section{Bacterial strains}

A high-resolution amplified fragment length polymorphism (AFLP) methodology was used to achieve the delineation of closely related Lactococcus lactis strains originating from previously a undefined mixed starter culture referred to as Ur $[2,20]$. Representative strains of Lactococcus lactis TIFN1-TIFN7 were used throughout this study. These strains represent single colony isolates from different genetic lineages. The strains were maintained as $15 \%$ glycerol stocks at $-80{ }^{\circ} \mathrm{C}$ and routinely grown in M17 broth (OXOID) with $0.5 \%$ (wt $/ \mathrm{vol}$ ) glucose or lactose addition (OXOID).

\section{In silico analysis of presence of prophages in genomic sequences}

The draft assemblies of genomic sequences of TIFN1-7 [2] were analysed by the prophage-predicting PHAST [21] Web server. This bioinformatics tool provides information on prophage completeness of the predicted phage-associated regions defined according to how many genes/proteins of a known phage the region contained: intact $(\geq 90 \%)$, questionable $(90-60 \%)$, and incomplete $(\leq 60 \%)$.

\section{Cell growth, prophage induction and purification}

Overnight cultures in M17 broth were diluted up to different $\mathrm{OD}_{600}(0.05,0.1,0.2$ and 0.3$)$ depending on the assays and allowed to grow for $1 \mathrm{~h}$ at $30^{\circ} \mathrm{C}$ before mitomycin $\mathrm{C}$ (MitC) was added (final concentrations of 0.3 , $0.5,1$ and $1.5 \mu \mathrm{g} / \mathrm{ml}$ were tested). For control purposes, the same diluted cultures without MitC were used. Incubation proceeded for 6 or $7 \mathrm{~h}$ and the turbidity at $600 \mathrm{~nm}$ was monitored at $1 \mathrm{~h}$ intervals.

For applied environmental stress experiments the overnight cultures were diluted to $\mathrm{OD}_{600}=0.05$. After $1 \mathrm{~h}$ of growth under standard conditions the cells were centrifuged at $5000 \mathrm{x} \mathrm{g}, 30{ }^{\circ} \mathrm{C}$ for $10 \mathrm{~min}$ to spin down the cells and the growth medium (supernatant) was discarded. At this point stress conditions were applied to the culture: the cell pellets were re-suspended in the same volume of corresponding media prepared in advance (LM17 (undiluted), 0.4-fold concentration of LM17, $1 \% \mathrm{NaCl}$, $2 \% \mathrm{NaCl}, 0.3 \mu \mathrm{g} / \mathrm{ml} \mathrm{MitC}$ ) and pre-heated to $30{ }^{\circ} \mathrm{C}$ in order to minimize temperature stress. For the temperature stress the medium was pre-heated to $34{ }^{\circ} \mathrm{C}$. Incubation of cultures was continued at corresponding temperatures $\left(30{ }^{\circ} \mathrm{C}\right.$ or $\left.34^{\circ} \mathrm{C}\right)$ in water bath.

Phage particles were isolated from the culture supernatants 6-7 $\mathrm{h}$ after the addition of MitC or after changing growth conditions essentially as described earlier [22]. Bacterial cells and debris were removed by centrifugation $5000 \times \mathrm{g}$ for $15 \mathrm{~min}$ at $4^{\circ} \mathrm{C}$. The supernatant was filtered through $0.22-\mathrm{mm}$ pore-size Minisart ${ }^{\circ}$ high flow PES Syringe Filters (Sartorius, Cat \#16532---GUK). The pH of the cleared sterile supernatants was adjusted to $\sim 7$ and the samples were either directly used for gel electrophoresis or further purified and concentrated by PEG/NaCl: 0.25 volumes of a solution containing $20 \%$ polyethylene glycol 8000 (PEG) and $2.5 \mathrm{M} \mathrm{NaCl}$ (the final concentration is $4 \%$ PEG, $0.5 \mathrm{M} \mathrm{NaCl}$ ) was added. The mixture was kept at $4^{\circ}$ $\mathrm{C}$ overnight and then centrifuged at $11,000 \times \mathrm{g}$ for $1 \mathrm{~h}$ to precipitate phage particles. The phage particles were suspended in SM buffer $\left(100 \mathrm{mM} \mathrm{NaCl}, 8 \mathrm{mM} \mathrm{MgSO}_{4}\right.$, 
$50 \mathrm{mM}$ Tris- $\mathrm{Cl}$ (pH 7.5)) in 1/160th of original culture volume. It has been shown [23] that these bacteriophage PEG based precipitation conditions do not co-precipitate chromosomal or other contaminating DNA or proteins.

\section{Electron microscopy}

For negative staining transmission electron microscopy (TEM), $5 \mu \mathrm{L}$ of concentrated phage sample was applied to a 400 mesh copper grid supplied with a formvar/carbon film and incubated for $5 \mathrm{~min}$. The grid was then stained with $2 \%$ uranyl acetate for $1 \mathrm{~min}$ and allowed to dry. Grids were observed in a JEOL JEM1011 transmission electron microscope at $80 \mathrm{KV}$ and photographed with a $2 \mathrm{Kx} 2 \mathrm{~K}$ Veleta digital camera (SIS Olympus).

For cryo-TEM, 300 mesh copper Quantifoil 2/2 grids were exposed to a glow-discharge in air prior to being used. Four microliters of phage solution was applied to each grid. Blotting and vitrification in liquid ethane were carried out with a Vitrobot Mark IV instrument (FEI Co.). Grids were then transferred to a Gatan CT 3500 cryostage and analyzed in a JEOL JEM2100 transmission electron microscope. Images were recorded at $200 \mathrm{KV}$ under low-dose conditions with a $4 \mathrm{~K} \times 4 \mathrm{~K}$ Gatan US4000 digital camera.

\section{Assaying the bacteriophage DNA content in samples by gel electrophoresis}

Phage capsids were disrupted by incubation of aliquots of either sterile supernatants or concentrated phage suspensions to liberate the phage DNA by incubating the samples with 0.2 volumes of SDS-EDTA dye mixture $(0.8 \%(v / v)$ SDS, $60 \mathrm{mM}$ EDTA, 0.5\% bromophenol blue, $0.5 \%$ xylene cyanol FF and $40 \%(w / v)$ sucrose) for $5 \mathrm{~min}$ at $65{ }^{\circ} \mathrm{C}$. The samples were directly loaded onto agarose gel.

Several electrophoresis runs were performed overnight at low field strength $(0.5 \mathrm{~V} / \mathrm{cm})$, on $0.3 \%$ agarose with $2 \%$ agarose supporting layer, in TAE, $20 \mathrm{~cm}$ gel length, $20 \mathrm{~h}$ (Additional file 1: Figure S1A). Selected samples (Additional file 1: Figure S1B) were resolved using fieldinversion gel electrophoresis (FIGE, PIppin Pulse (Sage Science)), $1 \%$ Lonza SeaKem ${ }^{\circ}$ GOLD agarose in 0.5-fold concentration TBE, length of gel $10 \mathrm{~cm}$, using the following instrument settings: $75 \mathrm{~V}(5 \mathrm{~V} / \mathrm{cm})$; A. Forward Time at start of run, $150 \mathrm{msec}$; B. Reverse Time at start of run, 50 msec; C. Increment added to A at each step, 30 msec.; D Increment added to B at each step, $10 \mathrm{msec}$.; E. Increment added to $C$ at each step, $3 \mathrm{msec}$ F. Increment added to $\mathrm{D}$ at each step, 1 msec.; number of steps per cycle 81 , total run duration $20 \mathrm{~h}$.

For quantification purposes standard electrophoresis conditions $(0.7 \%$ TAE agarose containing GelGreen, gel length $15 \mathrm{~cm}, 3-4 \mathrm{~V} / \mathrm{cm}, 1-3 \mathrm{~h}$ ) were applied. A single band between 24 and 48 bp was consistently observed in all samples.

Gels were scanned and analysed by blue transilluminator gel documentation system (Uvitec Alliance 4.7 Imager equipped with Safelight table and Safelight emission filter).

\section{Estimation of phage DNA content}

The DNA bands were visualized under blue illumination (Uvitec Alliance 4.7 Imager equipped with Safelight table and Safelight emission filter) and the images were used to estimate the amount of DNA via densitometry by UVIband software. DNA ladders GeneRuler High Range Ladder or $\lambda$ mix 19 (Thermo Scientific) were used to indicate high range molecular weight DNA species (10 to $48 \mathrm{kbp}$ ). DNA quantification was achieved by comparison with band intensities of known amounts of bacteriophage $\lambda$ DNA (Thermo Scientific).

The concentration of phage particles was derived based on the phage DNA concentration assuming an average phage size of $40 \mathrm{kbp}$ and $650 \mathrm{~g} / \mathrm{mol}$ molecular weight of 1 base pair.

$$
\text { number of copies }=\frac{\left(\text { DNA amount }[n g] \cdot 6.022 \cdot 10^{23}\left[\frac{1}{\text { mole }}\right]\right)}{\left(\text { DNA length }[b p] \cdot 10^{9}\left[\frac{n g}{g}\right] \cdot 650\left[\frac{g}{\text { mole } \cdot b p}\right]\right)}
$$

In $\mathrm{PEG} / \mathrm{NaCl}$ precipitated samples phage particle concentration in original supernatants was derived after correction for concentration factor.

\section{Prophage curing}

Cultures of L. lactis TIFN1, TIFN2 and TIFN4 were exposed to $1 \mu \mathrm{g} / \mathrm{ml}$ mitomycin C (MitC) during $6 \mathrm{~h}$ similar to the prophage induction procedure. Subsequently the cultures were diluted $\left(10^{5}, 10^{6}, 10^{7}\right.$ times $)$ and plated on M17 medium supplemented by $0.5 \%$ lactose. Individual colonies were purified and screened by colony PCR using a primer pair targeting P335 group phage sequence [24].

Absence of the amplified fragment indicated potential loss of prophage DNA from bacterial chromosome. The resulting strains were TI1c, TI2c, TI4c - the prophage cured derivatives of TIFN1, 2 and 4 respectively.

\section{Plasmid construction}

The plasmid pSA100 was generated by inserting an annealed pair of synthetic oligonucleotides encoding CP25 constitutive artificial promoter [25] 5' - TCGAC CTTTGGCAGTTTATTCTTGACATGTAGTGAGGGG GCTGGTATAATCACATAGTACTGTTA - 3' and 5' GATCTAACAGTACTATGTGATTATACCAGCCCCCT CACTACATGTCAAGAATAAACTGCCAAAGG - 3' into pSEUDO-GFP [26] between the SalI and BglII sites. Next, the EcoRI/BamHI fragment of pSA100 carrying 
the CP25 promoter, $g f p$ (the gene of the superfolder variant of green fluorescent protein, GFP [27]), and the transcription terminator was subcloned into corresponding sites of pIL253 [28] giving rise to pIL-JK2. pIl-SA07 was derived by inserting gene coding for mCherry from pSA047 [29] between the CP25 promoter and the transcription terminator of pIL-JK2 replacing the $g f p$.

\section{Transformation}

Competent lactococcal cells of strain TIFN2 and TI2c were prepared for electrotransformation in osmotically stable media containing $0.5 \mathrm{M}$ sucrose and glycine to weaken cell wall essentially as described by Holo, $\mathrm{H}$. [30]. For L. lactis TIFN1 and its derivative TI1c a modification had to be applied because these strains failed to grow when inoculated directly into media supplemented with glycine at concentrations above $0.5 \%$. The modification of the method implied progressive adaptation to higher glycine concentrations by repeatedly inoculating $1 \mathrm{~mL}$ of the overnight culture from the previous day into $10 \mathrm{~mL}$ of fresh SGGM17 (M17 medium supplemented with $0.5 \%$ glucose, $0.5 \mathrm{M}$ sucrose and glycine) with $0.5 \%$ glycine increments until reaching the highest concentration tested $(2.25 \%)$. Stock cultures of these strains in the highest glycine concentration were prepared in $15 \%(\mathrm{v} / \mathrm{v})$ glycerol and referred to as glycine adapted cells (GAC); the culture stocks of GAC were stored at $-80{ }^{\circ} \mathrm{C}$ until further use.

The GAC TIFN1 and TI1c cultures pre-grown overnight in SGLM17 media (M17, 0.5 M sucrose, 0.5\% lactose and $2.25 \%$ glycine) were re-inoculated into fresh SGL17M and grown to $\mathrm{OD}_{600}$ of 0.9. Cells were harvested by centrifugation at $6000 \times \mathrm{g}, 4^{\circ} \mathrm{C}$ for $20 \mathrm{~min}$ and washed once in 1 volume ice-cold washing buffer $(0.5 \mathrm{M}$ sucrose, $10 \%$ glycerol). A second washing step was performed in 0.5 volume ice-cold EDTA washing buffer (0.5 M sucrose, 10\% glycerol and 0.05 M EDTA), followed by a third washing step in 0.25 volume ice-cold washing buffer. Then the cells were resuspended in 0.01 volume washing buffer. Aliquots of $40 \mu \mathrm{l}$ were used directly for transformation or stored at $-80^{\circ} \mathrm{C}$.

Each aliquot of competent cells was mixed with 1-2 $\mu \mathrm{l}$ (500 ng) of plasmid DNA and then transferred to an ice-cooled electroporation cuvette (2-mm electrode gap) and exposed to a single electrical pulse. The pulse was delivered by the Gene Pulser Xcell Electroporation Systems (Bio-Rad) at $2500 \mathrm{~V}, 25 \mu \mathrm{F}, 200 \Omega$ resulting in time constants of 4.5 to $5 \mathrm{~ms}$. Immediately following the discharge $1 \mathrm{ml}$ cold recovery medium (M17, $0.5 \mathrm{M}$ sucrose, $0.5 \%$ lactose, $20 \mathrm{mM} \mathrm{MgCl}$ and $2 \mathrm{mM} \mathrm{CaCl}_{2}$ ) was added. The cuvette was kept on ice for $5 \mathrm{~min}$ and then incubated $2 \mathrm{~h}$ at $30{ }^{\circ} \mathrm{C}$. The cells were spread on selection plates (LM17, 1.5\% agar, $0.5 \mathrm{M}$ sucrose and $3 \mu \mathrm{g} /$ $\mathrm{ml}$ erythromycin) and incubated at $30{ }^{\circ} \mathrm{C}$ for two days. The procedure resulted in transformation efficiencies

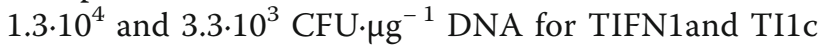
respectively. All strains were verified for its identity and the presence/absence of prophage by strain-specific PCR probes (Table 1).

\section{PCR}

Colony PCR was carried out on bacterial cells, grown on LM17 agar plates, by using DreamTaq DNA polymerase (Thermo Scientific) in $25 \mu \mathrm{l}$ total volume. The PCR cycling program consisted of $95{ }^{\circ} \mathrm{C}$ for $3 \mathrm{~min}$, then 25 cycles of $30 \mathrm{~s}$ at $95^{\circ} \mathrm{C}, 1 \mathrm{~min}$ at $53^{\circ} \mathrm{C}$, and $1 \mathrm{~min}$ at $72^{\circ} \mathrm{C}$, with an additional step of $5 \mathrm{~min}$ at $72^{\circ} \mathrm{C}$. PCR primers used are listed in Table 1, the strain specific primers, targeting genetic markers specific for TIFN $(1 \& 5)$ and TIFN $(2 \& 4)$ were as described earlier [2].

\section{Competition experiment}

Overnight cultures of transformed strains: TIFN1/ pIL-JK2, TIFN1/pIL-SA07, TI1c/pIL-JK2, TI1c/pIL-SA07

Table 1 PCR primers used in this study

\begin{tabular}{|c|c|c|c|}
\hline target prophage & code & name & Sequence \\
\hline \multirow[t]{6}{*}{$\overline{\text { proФ1 }}$} & P1 & pro1-Inch5F & GTTGTGGAGACTTGACGCAGCAA \\
\hline & P2 & pro1-Inch5R & CCTTCAAAACCTAGAAAATGGC \\
\hline & P3 & pro1-Inch3F & GGATGAGAAAAACATTCAATTACAAACA \\
\hline & P4 & pro1-Inch3R & CATCAATGAACGTTTATACCCATATTAC \\
\hline & strain specific & TIFN1\&5f & TCGCTGTCATTGGTATCAGC \\
\hline & & TIFN1\&5f & CCAAATTCCGCAGTGTTTC \\
\hline \multirow[t]{6}{*}{$\operatorname{pro} \Phi 2 / 4$} & P1 & pro2-Inch5F & ATGTTGAAATCAATGACGACTCAGTT \\
\hline & P2 & pro2-Inch5R & CACGTTACTAAAAAGGCAAAAAAAGAT \\
\hline & P3 & pro2-Inch3F & CGTCGATTGAATGCGAATAAACTAT \\
\hline & P4 & pro2-Inch3R & CAATATACTGTCACACACTCAAAGAC \\
\hline & strain specific & TIFN2\&4f & TGGCTTAGTATTGGCACCTCA \\
\hline & & TIFN2\&4r & AGCTGTTCGACCGACACTIT \\
\hline
\end{tabular}


were each diluted to $\mathrm{OD}_{600} 0.01$ with fresh LM17 supplemented with $5 \mu \mathrm{g} / \mathrm{ml}$ erythromycin and mixed pairwise 1:1 in four different combinations (in duplicate). Wild type and cured strains were mixed in reciprocal combinations: GFP-labelled wild type with mCherry-labelled cured strain (TIFN1/pIL-JK2 and TI1c/pIL-SA07) and mCherry-labelled wild type with GFP-labelled cured strain (TIFN1/pIL-SA07 and TI1c/pIL-JK2). Control cultures included the mix of GFP- and mCherry-labelled both wild type strains (TIFN1/pIL-JK2 with TIFN1/ pIL-SA07) and GFP- and mCherry-labelled cured derivatives (TI1c/pIL-JK2 with TI1c/pIL-SA07). The mixed cultures were daily propagated by diluting $1 \%$ of the overnight culture with fresh medium during 5 days. Ratio between GFP and mCherry expressing cells in samples from day $0,1,2$ and 5 were analysed by flow cytometry. At day 2 the cultures were also spread on LM17 plates supplemented with $5 \mu \mathrm{g} / \mathrm{ml}$ erythromycin and the ratio between green (GFP) and red (mCherry) colonies in the four mixed cultures was quantified in images acquired using fluorescence Imager UVITEC Alliance 7 series (UVITEC, Cambridge, Great Britain), equipped with Blue excitation light source and emission filter $565 \mathrm{~nm}$ for detection of the GFP and Red excitation light source and emission filter $695 \mathrm{~nm}$ for detecting mCherry.

\section{Flow cytometry}

Samples were analysed by using a BD FACS Aria $^{\mathrm{Tx}}$ III flow cytometer (BD Biosciences, San Jose, CA). The cytometer was set up using a $85 \mu \mathrm{m}$ nozzle and was calibrated daily using BD FACSDiva Cytometer Setup and Tracking (CS\&T) software and CS\&T Beads (BD Biosciences). $488 \mathrm{~nm}$, air-cooled argon-ion laser and the photomultipliers with $488 / 10$ band pass filter for forward and side scatter and with filter 530/30 nm (with 502 LP filter) for the detection GFP were used. mCherry was excited with yellow-green $561 \mathrm{~nm}$ laser and detected by a 610/ $20 \mathrm{~nm}$ with LP $600 \mathrm{~nm}$ filter. FSC and SSC voltages of 300 and 350, respectively, and a threshold of 1200 on FSC was applied to gate on the bacterial cell population. The stopping gate was set to 10,000 events. Data were acquired by using BD FACSDiva ${ }^{\text {Tw }}$ software and analysed by using FlowJo flow cytometry analysis software (Tree Star, Ashland, OR).

\section{Results}

In silico analysis of potentially inducible prophage pool from a dairy mixed starter culture

An in silico analysis of genomic sequence assemblies of the 7 representative Lactococcus lactis strains (labelled as TIFN1-TIFN7) was carried out. Each of these strains are representatives of the $7 \mathrm{~L}$. lactis genomic lineages found in the starter culture referred to as Ur [2]. Putative prophage DNA sequences were identified using manual genome browsing based on frequent homology of the ORFs in the chromosomal regions to known phage proteins as well as by using a Web-based prophage-predicting tool PHAST (Phage Search Tool, available at http://phast.wishartlab.com/) [21]. Regions identified as "intact" or "questionable" prophage by PHAST algorithm and manual inspection were considered as potential prophages. All strains in our analysis were predicted to be lysogens and carry at least 1 prophage on the chromosome (see Table 2).

As anticipated, all predicted bacteriophages were found to belong to the P335 group of Siphoviridae phages. Because the chromosomal sequence information consists of separate pseudo-assembled scaffolds, exact prophage locations on the bacterial chromosomes and their correct genetic makeup were difficult to determine.

\section{Mitomycin C induced phage release}

To experimentally confirm the ability of Ur prophages to undergo lysogenic/lytic conversion, exponentially growing cells were exposed to mitomycin $\mathrm{C}$ (MitC) treatment. Seven representative strains from the complex dairy culture Ur (strains TIFN1, TIFN2, TIFN3, TIFN4, TIFN5, TIFN6, TIFN7) along with two control L. lactis strains IL1403 and L. lactis MG1363 were used in this study. $L$. lactis IL1403 can be considered as a positive control since it was shown to possess six prophages related sequences [8]. L. lactis MG1363 is taken as a negative control because induction of prophages has never been reported in the literature for this strain [31].

Using supernatants of the induced cultures, attempts have been made to identify sensitive strains within the Ur consortium (54 Ur isolates) as well as among 7 unrelated strains (industrial $L$. lactis isolates, Laboratory of Food Microbiology, in-house culture collection), and $L$. lactis MG1363 and IL1403. All these lactococcal strains were challenged with supernatants derived from the MitC treated cultures in a spot assay. No sensitive host strains could be identified for any of supernatants (not shown) as no plaques were produced on the cell lawns.

In contrast, phage-size DNA bands (25-45 kbp) were readily visible on agarose gels after treatment with SDS/ EDTA in nearly all cleared, filtered supernatants of MitC treated Ur strains (Fig. 1). Upon MitC induction, DNA corresponding to phage DNA size, between 25 and 45 $\mathrm{kbp}$, is readily visible in all samples except in the negative control strain L. lactis MG1363 as anticipated, and in L. lactis TIFN3. The latter strain showed visible DNA bands only after concentrating the sample (see below), suggesting that this strain released the lowest amount of phage DNA. The size of the bacteriophage genome was analysed more accurately for several samples by either long overnight electrophoresis runs at low field strength or by field-inversion gel electrophoresis (FIGE). Molecular weights of pro $\Phi 1$ and pro $\Phi 5$ were estimated at 40.7 
Table 2 Summary of predicted prophages in 7 sequenced TIFN strains

\begin{tabular}{|c|c|c|c|c|c|}
\hline STRAIN & NAME & REGION LENGTH & COMPLETENESS & MOST SIMILAR & DETAILS \\
\hline \multirow[t]{2}{*}{ TIFN1 } & proФ1_1 & $56.1 \mathrm{~Kb}$ & intact & Lactococcus phage blL309 & integrase, capsid, tail, portal, terminase, protease \\
\hline & proФ1_2 & $49.2 \mathrm{~Kb}$ & questionable & Lactococcus phage TP901-1 & integrase, transposase, terminase, lysin \\
\hline \multirow[t]{2}{*}{ TIFN2 } & proФ2_1 & $43 \mathrm{~Kb}$ & intact & Lactococcus phage blL309 & integrase, capsid, tail, portal, terminase, protease, lysin \\
\hline & proФ2_2 & $57.7 \mathrm{~Kb}$ & intact & Lactococcus phage blL309 & integrase, tail, portal, terminase, protease \\
\hline TIFN3 & proФ3 & $36.8 \mathrm{~Kb}$ & questionable & - & integrase, transposase \\
\hline \multirow[t]{2}{*}{ TIFN4 } & proФ4_1 & $44.1 \mathrm{~Kb}$ & intact & Lactococcus phage blL309 & integrase, capsid, tail, portal, terminase, protease \\
\hline & proФ4_2 & $60 \mathrm{~Kb}$ & intact & Lactococcus phage blL309 & integrase, tail, portal, terminase, protease \\
\hline \multirow[t]{2}{*}{ TIFN5 } & proФ5_1 & $47.5 \mathrm{~Kb}$ & questionable & Lactococcus phage TP901-1 & integrase, transposase, terminase \\
\hline & proФ5_2 & $31 \mathrm{~Kb}$ & intact & Lactococcus phage blL309 & integrase, capsid, tail, portal, terminase, protease \\
\hline \multirow[t]{2}{*}{ TIFN6 } & proФ6_1 & $31 \mathrm{~Kb}$ & questionable & Lactococcus phage TP901-1 & tail, transposase, terminase, Lysin \\
\hline & proФ6_2 & $60.7 \mathrm{~Kb}$ & intact & Lactococcus phage blL309 & $\begin{array}{l}\text { integrase, capsid, tail, transposase, head, portal, } \\
\text { terminase, protease, lysin }\end{array}$ \\
\hline \multirow[t]{2}{*}{ TIFN7 } & proФ7_2 & $42.1 \mathrm{~Kb}$ & questionable & Lactococcus phage phiLC3 & capsid, transposase, terminase \\
\hline & proФ7_3 & $43.8 \mathrm{~Kb}$ & questionable & - & transposase, terminase \\
\hline
\end{tabular}

kbp and pro $\Phi 2$ was estimated at $39.5 \mathrm{kbp}$ (Additional file 1: Figure S1). Moreover, 14 additional Ur strains belonging to lineages 1 and 5 [2] were analysed and all of them released detectable amounts of phage DNA upon MitC induction (Additional file 2: Figure S2).

\section{Phage morphology and dimensions}

Electron microscopic examination was performed to confirm that the released large DNA molecules belong to expressed bacteriophages. PEG/NaCl concentrated post-induction supernatants were subjected to microscopic observations after removal of residual PEG by chloroform treatment. A representative electron micrograph of a negatively stained specimen derived from $L$. lactis TIFN1 (designated as pro $\Phi 1$, see Fig. 2a), shows a capsid of $55 \pm 2 \mathrm{~nm}$, which is similar to those of other members of the P335 group phages [32], but lacking a tail structure. We also consistently observed an electron dense spot within the head structure (arrow). This may indicate the presence of a large macromolecular complex in or attached to the capsid. Cryo-electron microscopy
(cryo-TEM) performed on the same sample clearly showed icosahedral shaped heads (Fig. 2b). The same tailless heads, albeit in much lower amounts we observed in $\mathrm{PEG} / \mathrm{NaCl}$ concentrated supernatants from cultures not subjected to MitC induction (uninduced cultures, Fig. 2c). In parallel, positive control culture of the lysogenic L. lactis strain SK11 [33] was subjected to MitC induction. Small phages with capsid dimensions 42 $\pm 2.4 \mathrm{~nm}$ and attached long tails $\sim 142 \mathrm{~nm}$ were observed in the SK11 concentrated supernatants (Fig. 2d). Only one of the analysed strains (L. lactis TIFN6) produced, in addition to tailless phage particles, also separated phage tail structures.

\section{Effect of induction conditions on cell growth and phage release}

To shed more light on the process of phage particle production, growth behaviour and phage yield were monitored simultaneously for relevant strains. To evaluate optimal conditions for prophage induction in the Ur strains TIFN1 to TIFN7, we varied the timing of

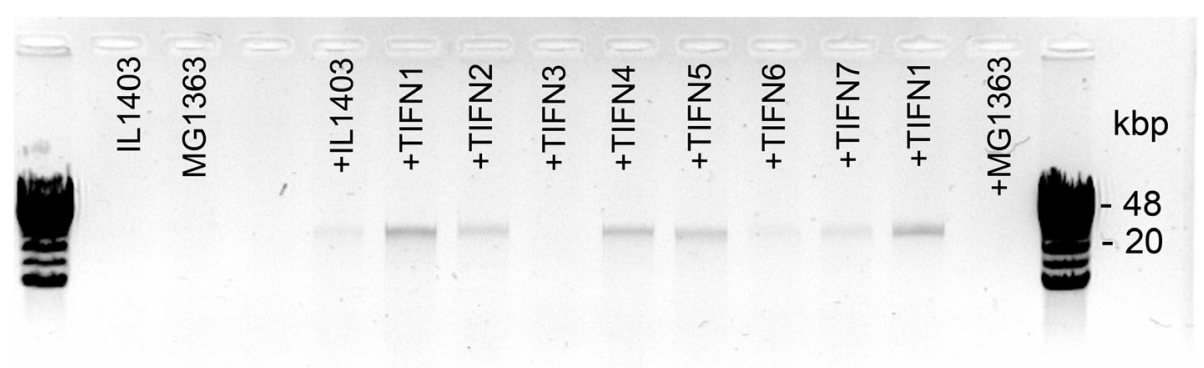

Fig. 1 Release of phage size DNA in supernatants of strains treated with Mitomycin C (MitC). Above each lane Lactococcus lactis strains TIFN1-7 are indicated along with control strains MG1363 and IL1403, (+) indicate samples subjected to $1 \mu \mathrm{g} / \mathrm{ml}$ MitC treatment (initial OD $\mathrm{D}_{600}$ was 0.2 ) 

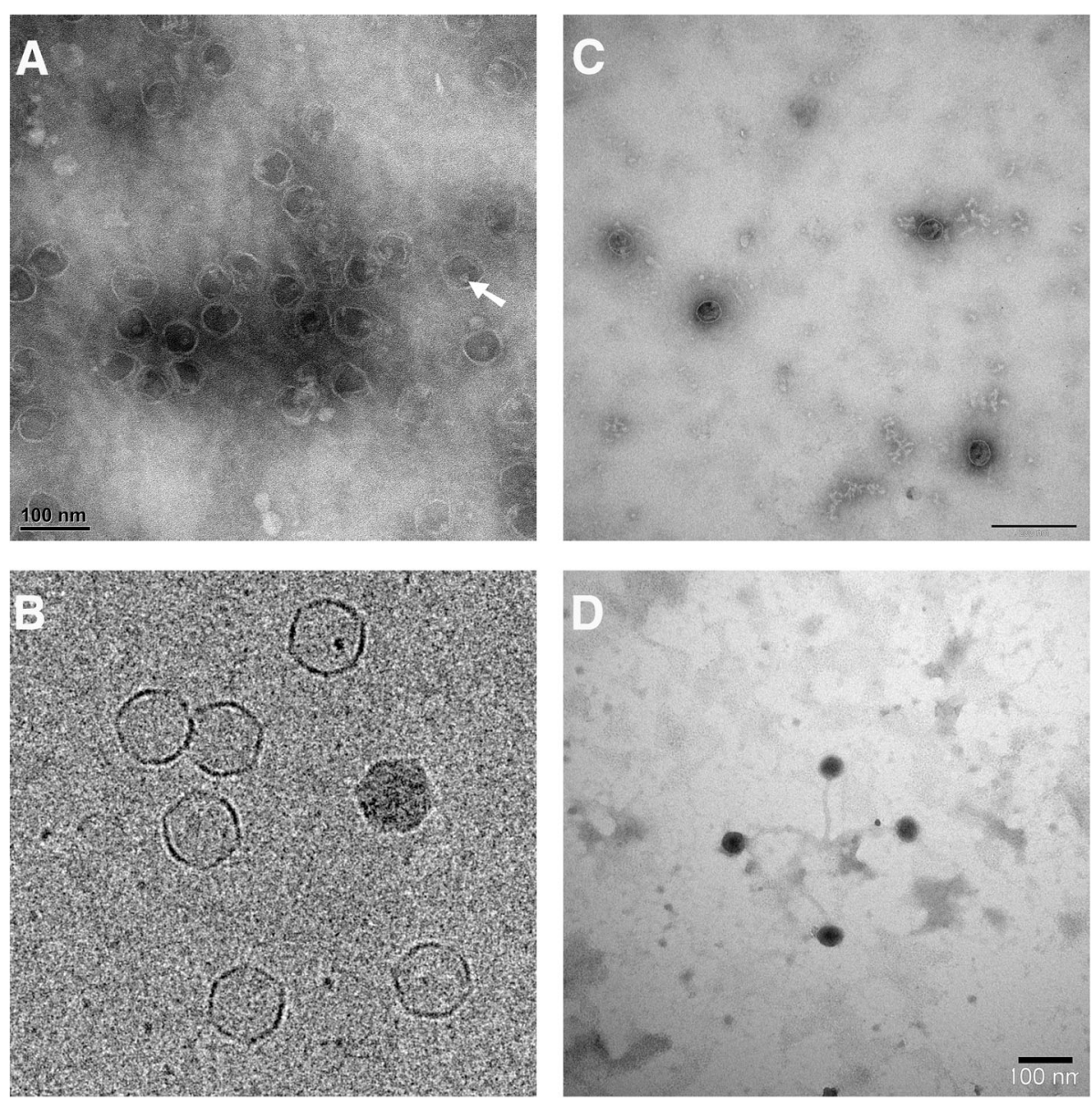

Fig. 2 Electron micrograph of the released bacteriophages. a Negative (uranyl acetate) staining Transmission Electron Microscopy (TEM) image of a typical bacteriophage (proФ1). The white arrow indicates a characteristic electron density inside the heads. b Cryo-TEM image of proФ1. c Bacteriophage pro $\Phi 5$, released from TIFN5 under non-inducing conditions. d Bacteriophage SK11 with intact tails released from SK11

strain after MitC induction

induction during culture growth and studied the release of phage crop as a function of the concentration of the inducer mitomycin $\mathrm{C}(\mathrm{MitC})$. Addition of MitC at the onset of exponential phase (initial optical density at $\left.600 \mathrm{~nm}, \mathrm{OD}_{600}=0.05\right)$ strongly inhibited growth of $L$. lactis TIFN1 at all tested MitC concentrations except for the lowest concentration $0.3 \mu \mathrm{g} / \mathrm{ml}$ used (Fig. 3a). We varied the initial culture $\mathrm{OD}_{600}$ and added the inducer after approximately 1 doubling $(1 \mathrm{~h})$. Increasing initial culture density from 0.05 to 0.3 (or from $\mathrm{OD}_{600}=0.1$ up to 0.6 at initiation of induction, Fig. 3) resulted in less growth inhibition. This effect inversely correlated with increasing MitC (0.5 to $1.5 \mu \mathrm{g} / \mathrm{ml})$ concentrations. Analysis of phage crop yield as a function of different conditions (Fig. 4) showed that the induction efficiency is dependent on the growth phase as well as on the inducer concentration. This is in agreement with earlier observations [34]. Initiation of induction at the late exponential phase, $\mathrm{OD}_{600}=0.4$ or 0.6 (or initial $\mathrm{OD}_{600}=0.2-0.3$ ), and elevated MitC concentrations generated significantly higher prophage induction and release of phage crop for all tested lysogenic strains. Some induction conditions resulted in a highly variable cell growth response (e.g. see Fig. 3b). Interestingly, conditions of maximum phage yields neither resulted in culture clearance nor in a decrease in optical density.

Induction dynamics performed for L. lactis TIFN1 and L. lactis TIFN5 at $20^{\circ} \mathrm{C}$ and $30^{\circ} \mathrm{C}$ showed maximum yields of phage crop at $30^{\circ} \mathrm{C}$ after MitC induction during 5-6 h (Fig. 5a). As expected, induction proceeded at a lower rate at $20^{\circ} \mathrm{C}$. Interestingly, the presence of phage DNA was even observed before addition of an inducer (a faint band is shown in Fig. 5a, time 0) in cultures grown at $30{ }^{\circ} \mathrm{C}$. Regarding this, we concentrated phage crops using $\mathrm{PEG} / \mathrm{NaCl}$ precipitation in order to compare the amount of phage DNA detected in L. lactis TIFN1 and TIFN5 cultures after MitC and spontaneous induction at the end of the incubation period (Fig. 5b). 

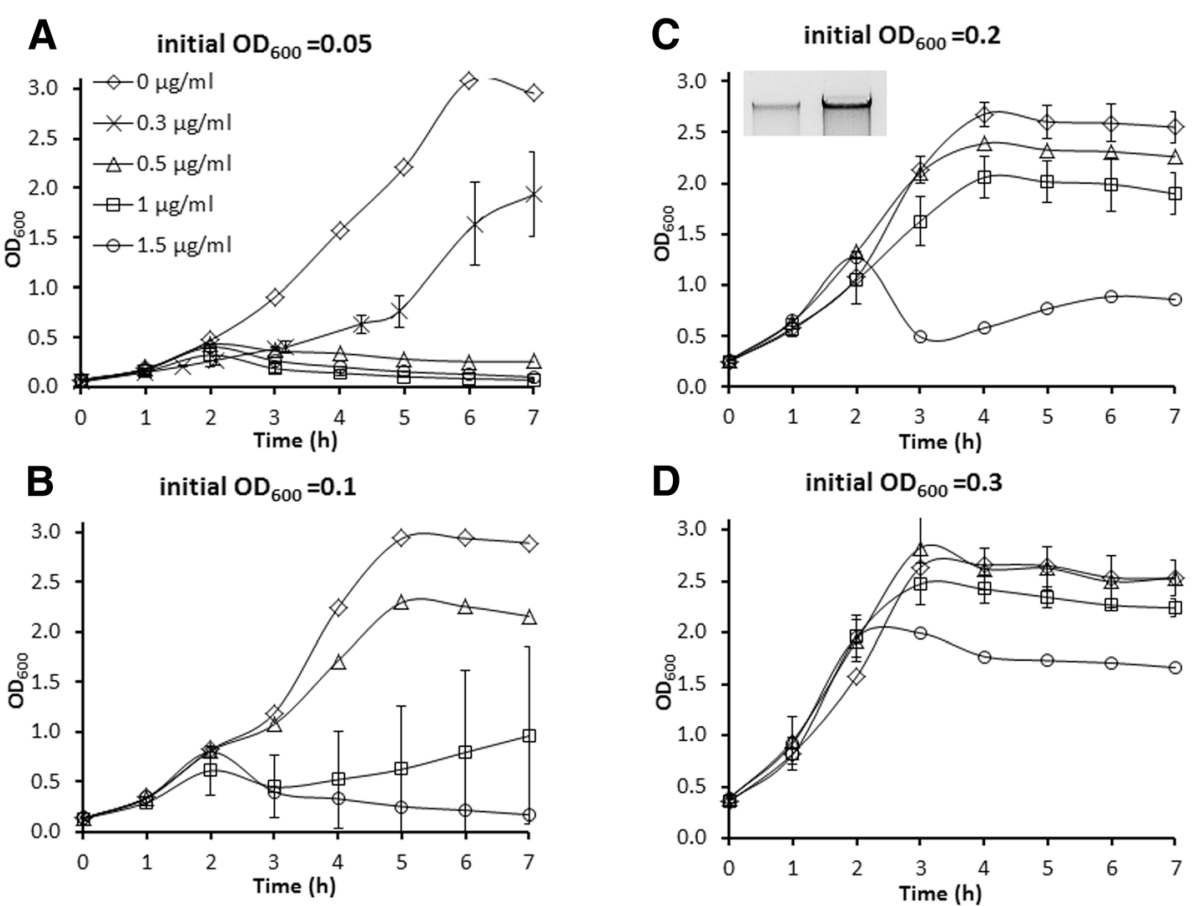

Fig. 3 Growth response of Lactococcus lactis TIFN1 to different induction conditions. Mitomycin C (MitC) induction of TIFN1 initiated at different growth phase $\left(\mathrm{OD}_{600}\right)$ and by different MitC concentrations. Initial $\mathrm{OD}_{600} 0.05$ (panel a), 0.1 (b), 0.2 (c), 0.3 (d) correspond to $\mathrm{OD}_{600} \sim 0.1,0.2,0.4$, 0.6, respectively, at the time point of MitC addition (after $1 \mathrm{~h}$ of growth without MitC). In graph $\mathrm{C}$, the insert shows phage DNA release at $7 \mathrm{~h}$ of the incubation period (left: spontaneous induction; right: MitC $(1 \mu \mathrm{g} / \mathrm{mL})$

Profuse phage release was observed, even in non-induced cultures.

\section{MitC driven and spontaneous prophage induction in Ur strains}

Once the optimal prophage induction conditions were established for strain TIFN1, we proceeded to analyse and compare the growth response and prophage release in the other representative lactococcal strains (L. lactis TIFN2, L. lactis TIFN3, L. lactis TIFN4, L. lactis TIFN5, L. lactis TIFN6 and L. lactis TIFN7) selected from Ur starter culture. MitC was added at a concentration of $1 \mu \mathrm{g} / \mathrm{mL}$ to growing cultures at late exponential phase (initial $\mathrm{OD}_{600}=0.2$, which corresponded to $\mathrm{OD}_{600}$ of $\sim$ 0.4 at the point of MitC addition after $1 \mathrm{~h}$ of growth). Induction was continued for $6 \mathrm{~h}$ at $30^{\circ} \mathrm{C}$. Non-induced cultures (no MitC added) were analysed as controls. The experimental conditions hardly affected growth of most of the strains (Fig. 6). Only cultures of L. lactis TIFN2 (Fig. 6a) and L. lactis TIFN4 (Fig. 6c), showed a growth arrest upon addition of MitC. Interestingly, the latter two strains belong to the subspecies lactis while the others belong to the susbspecies cremoris.

We estimated the phage DNA concentration in the supernatants by densitometric quantification of DNA in GelRed-stained agarose gels using as a reference $\lambda \mathrm{DNA}$ (Fig. 7). Determination of the DNA content allowed us to estimate the concentration of phage particles. Spontaneous prophage induction resulted in a phage crop of approximately $10^{9} \cdot \mathrm{ml}^{-1}$ phage particles in 6 out of 7 culture supernatants analysed. One exception is L. lactis TIFN3, which produced 10-fold less phage particles in the absence of an inducer. Only after concentrating the sample of this particular strain with $\mathrm{PEG} / \mathrm{NaCl}$, we were able to detect a prophage-related DNA band in the gel. Upon addition of MitC the concentration of phages in 6 out of 7 strains increased 2-20 times to approximately $10^{10} \cdot \mathrm{ml}^{-1}$ liberated phage particles.

\section{Change in spontaneous prophage induction at stress conditions}

To determine the potential effect of the environmental stress factors on the spontaneous prophage induction, we challenged exponentially growing cultures (initial $\mathrm{OD}_{600}=0.05$ with various stress conditions. The mild heat shock (temperature of incubation was suddenly changed from 30 to $34{ }^{\circ} \mathrm{C}$ ), osmotic up-shock (LM17 broth was supplemented with 1 and $2 \% w / v \mathrm{NaCl}$ ), and nutrient limitation (cultures were transferred from LM17 broth to 0.4-fold concentration LM17) were applied to cultures at $\mathrm{OD}_{600} \sim 0.1$. Different responses to the stress conditions were observed in the lysogenic strains (Table 3, Additional file 3: Figure S3 and Additional file 4: Figure S4). Slightly elevated temperature $\left(34^{\circ} \mathrm{C}\right)$ resulted in increased 


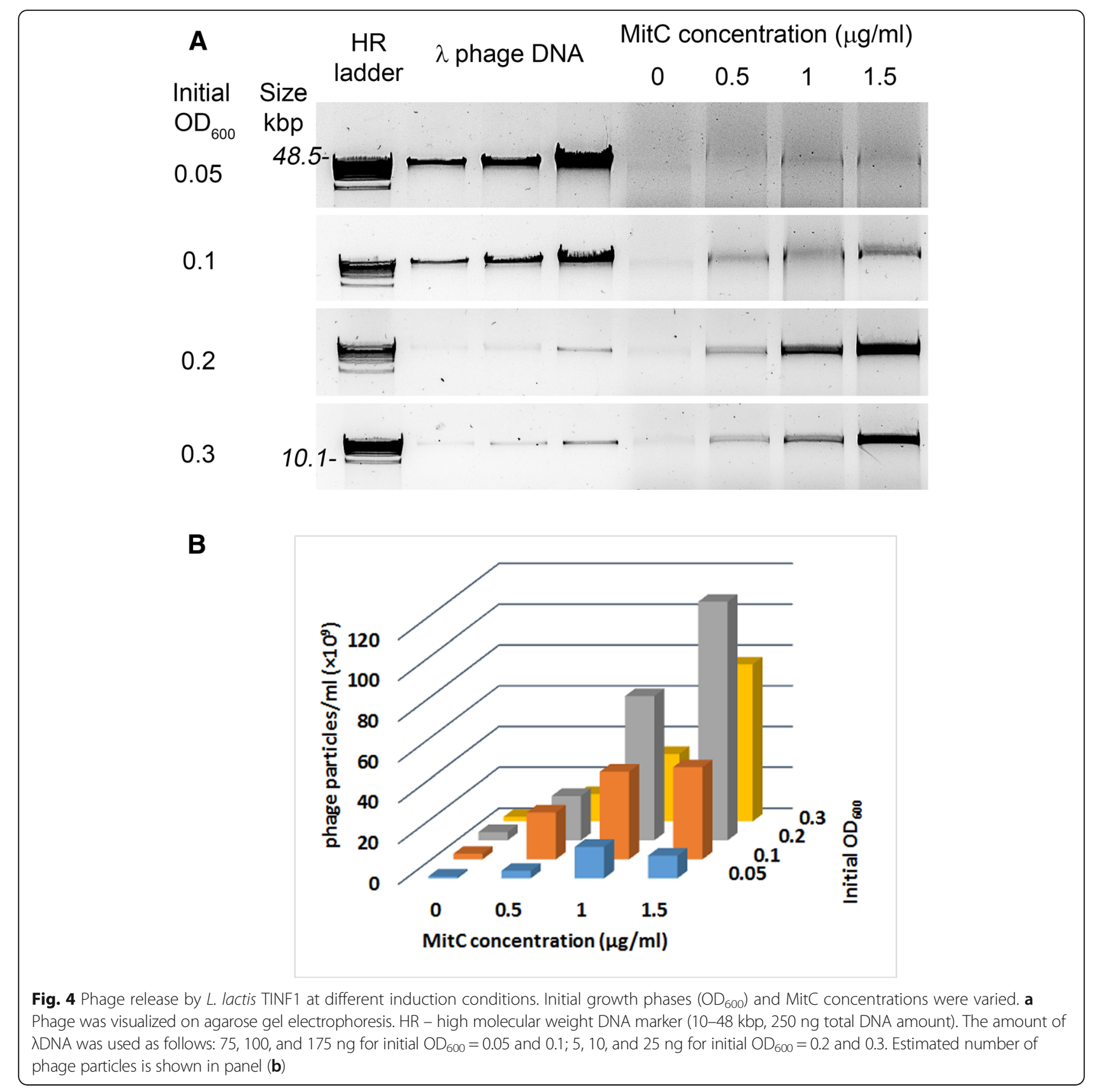

spontaneous prophage induction in 5 of the 7 strains tested (L. lactis TIFN1, TIFN2, TIFN4, TIFN5 and TIFN7). In $L$. lactis TIFN3 and L. lactis TIFN6, increased prophage induction was provoked by increased osmolarity. Interestingly, reduced nutrient availability, in contrast to other conditions resulted in slightly decreased prophage induction.

\section{Prophage curing, lysogen instability and continuous phage excision/DNA replication}

To determine the impact of the presence of prophages in the chromosome on the host fitness we isolated prophage-cured derivatives for several strains: TIFN1, TIFN2, and TIFN4. These strains were annotated TI1c, TI2c, and TI4c respectively. During the initial screening we found a high rate of prophage loss (1:30 to 1:60 of the screened colonies were found to be prophage-free), indicating a high degree of prophage excision. The strain identity and the absence of prophages were confirmed by using strain and phage specific PCR primers. Based on the available sequence information we predicted phage ends and their chromosomal insertions and used these predictions to design PCR primers for detecting and discriminating between (i) integrated prophage, 


\section{Time (h)}

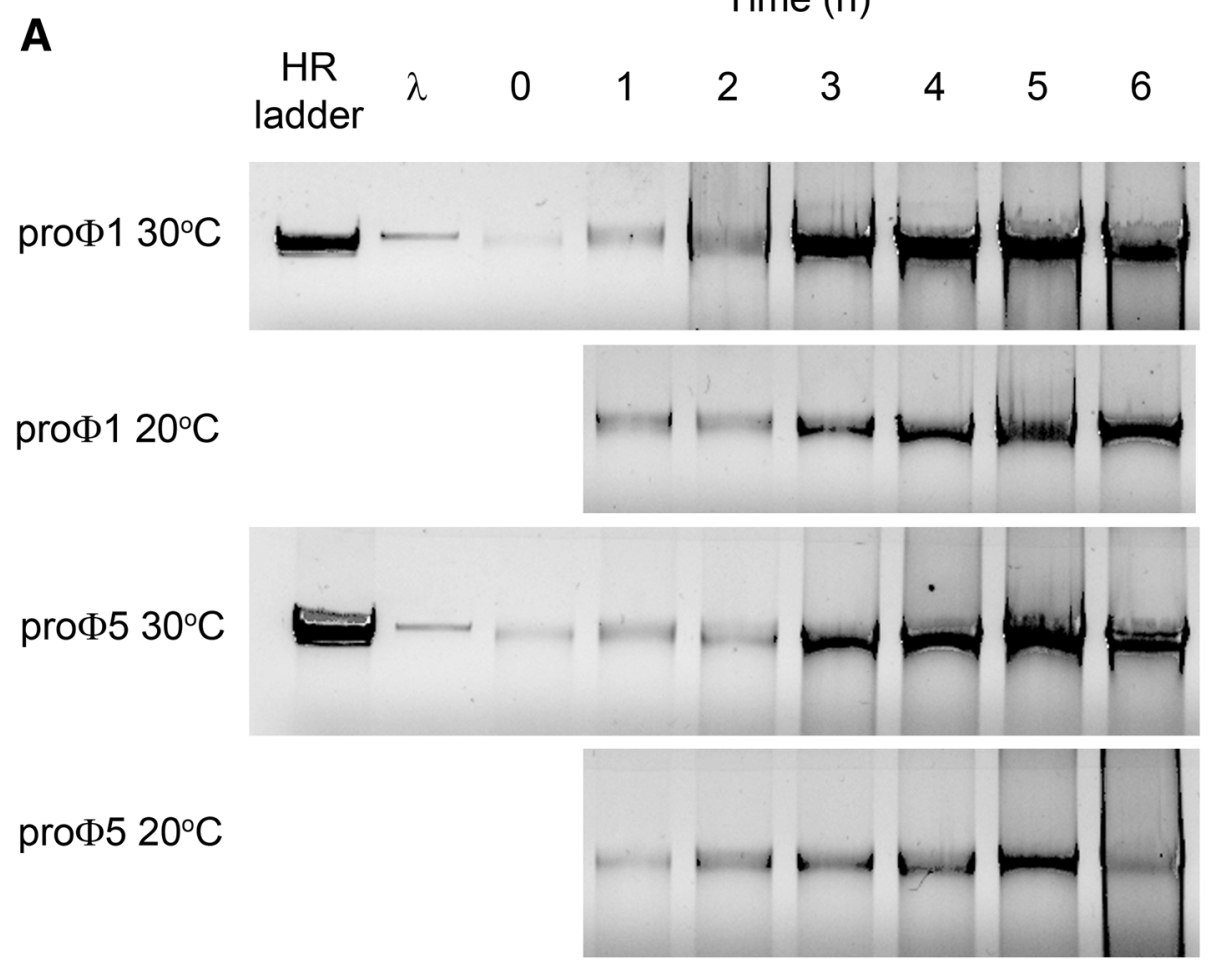

B

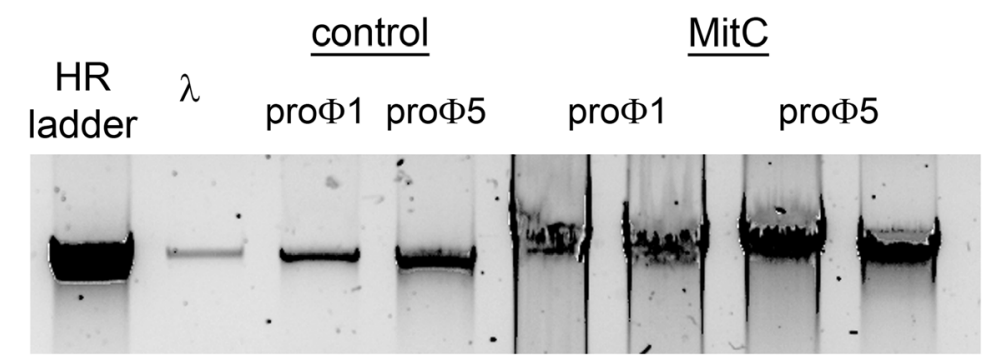

Fig. 5 Dynamics of phage release by L. lactis TIFN1 (proФ1) and L. lactis TIFN5 (proФ5). a Phage release from cultures (initial $\left.\mathrm{OD}_{600}=0.2\right)$ after treatment with MitC $(1 \mathrm{\mu g} / \mathrm{ml})$ and incubated at 20 and $30^{\circ} \mathrm{C}$ for $6 \mathrm{~h}$ was monitored by visualizing the DNA from the viral progeny throughout the incubation period on agarose gel electrophoresis. $\mathbf{b}$ Phage DNA from non-induced cultures and MitC-induced cultures (in duplicate) of the strains TINF1 and TINF5 at the end of the incubation period ( $6 \mathrm{~h})$ at $30^{\circ} \mathrm{C}$. $\lambda$ phage DNA (50 ng) is used as reference

encompassing either attR (P1/P2) or attL sites (P3/P4), (ii) circularized prophage (P2/P3) and (iii) prophage-free chromosome (P1/P4) when the prophage is excised. Colony PCR analysis (Fig. 8) of the three wild-type strains shows that: (i) the $\mathrm{P} 1 / \mathrm{P} 2$ as well as $\mathrm{P} 3 / \mathrm{P} 4$ primer pairs yield an amplicon in the wild type strains verifying the correct predicted location of the prophage on the bacterial chromosome; (ii) P2/P3 amplicon, indicating the presence of circular prophage species in non-induced wild type strains; and (iii) P1/P4 amplicon, detecting the chromosome with excised prophage, which was found to be present in non-induced wild type strains too. The latter two observations confirm our hypothesis that the prophages are continuously excised and replicating even without induction.

In contrast, only $\mathrm{P} 1 / \mathrm{P} 4$ primer pair yielded a PCR product for cured strains. P1/P4 sites are distant from each other by $\sim 40 \mathrm{~kb}$ if the prophage is present on the chromosome, thus no product is amplified in the PCR reaction. If the prophage is excised from the chromosome a short fragment (396 and 196 base pairs for TIFN1 and TIFN2 respectively) is predicted and observed. The colony PCR results for TIFN4 and its cured derivative TI4c (not shown) were exactly the same as TIFN2/TI2c. This confirms the specificity of the primers as well as successful curing of the three strains. 
A TIFN2

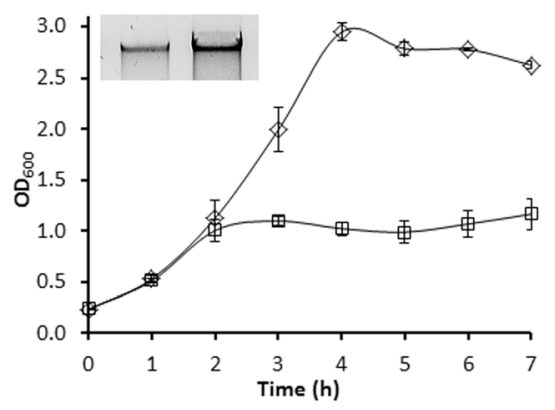

B TIFN3

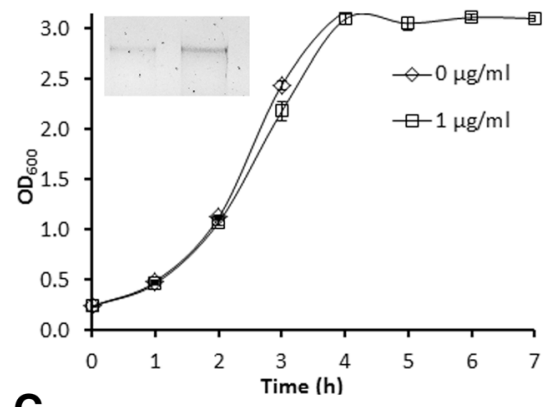

C TIFN4

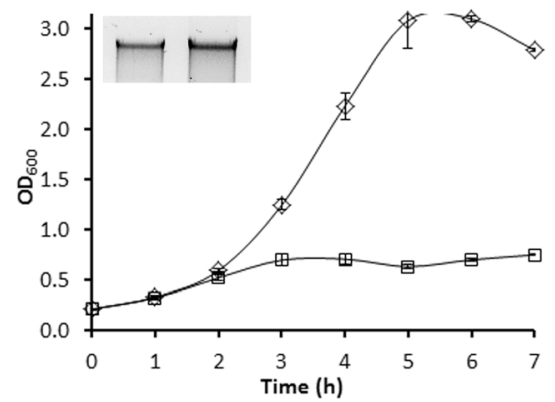

D TIFN5

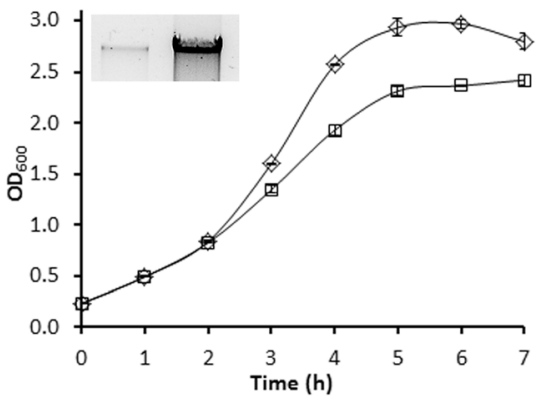

E TIFN6

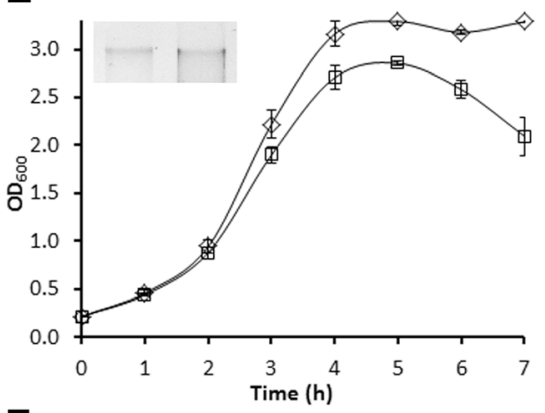

F $\quad$ TIFN7

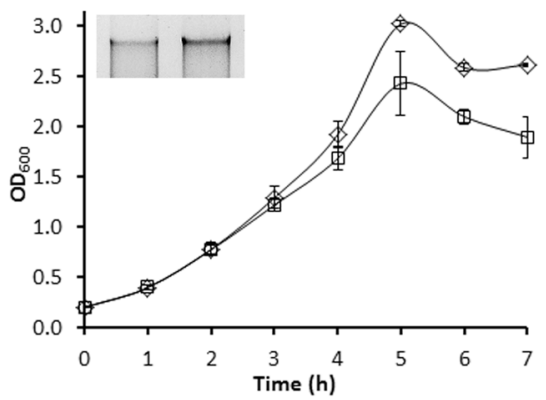

Fig. 6 Growth response of L lactis TIFN2 (a), TIFN3 (b), TIFN4 (c), TIFN5 (d), TIFN 6 (e) and TIFN7 (f) to 1 $\mu \mathrm{g} / \mathrm{ml}$ MitC induction. The induction was initiated at $\mathrm{OD}_{600}=0.4$. Initial $\mathrm{OD}_{600}$ was set to 0.2 resulting in $\mathrm{OD}_{600} \sim 0.4$ at the MitC induction start. To control samples (diamonds) no MitC was added. The inserts show phage DNA released at the end of the induction (time point $7 \mathrm{~h}$ ) for un-induced samples (left) and induced samples (right)

The prophages contribute to the host competitive advantage as revealed in competition experiment

To further elucidate the impact of carrying prophage sequences on host fitness we designed competition experiments in which the wild type strains and the prophagecured derivatives were labelled with either GFP or mCherry fluorescent proteins, encoded on plasmid and expressed from an artificial constitutive promoter. The GFP and mCherry expressing strains were mixed 1:1 in different combinations in duplicate and propagated in mixed cultures in LM17 medium. The cultures were diluted daily 1:100 and monitored during 5 days. To determine the change in the ratio between GFP- and mCherry-expressing cells in time 10,000 individual cells from each time point were analysed by flow cytometry
(Fig. 9a). Remarkably, expression of mCherry in lactococcal cells had a detrimental effect compared to the expression of GFP. The control combinations of both wild types (WT-GFP \& WT-mCherry) as well as both cured strains (cured-GFP \& cured-mCherry) showed the same pattern, GFP expressing cells overgrew mCherry expressing cells. After $24 \mathrm{~h}$ of growth the ratio GFP/ mCherry expressing cells in both control cultures were $70 \% / 30 \%$, by day 2 the ratio shifted to $\sim 85 \% / 15 \%$ and only GFP expressing cells remained in the cultures on day 5. In contrast, the experimental samples - the combination of WT-GFP \& cured-mCherry and cured-GFP \& WT-mCherry showed pattern of change different to each other as well as different to the control samples. mCherry-labelled cured cells were overgrown by the 


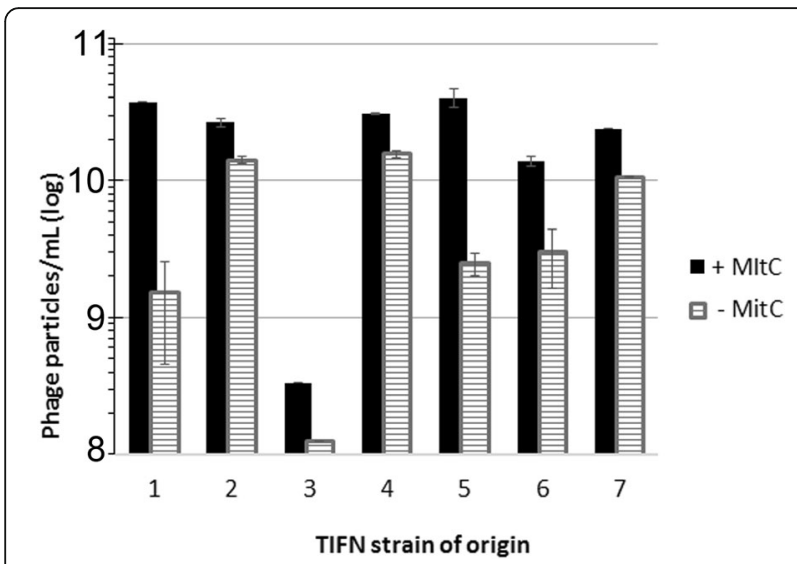

Fig. 7 Quantification of phage particles release in the absence and presence of MitC. TIFN1, TIFN2, TIFN3, TIFN4, TIFN5, TIFN6 and TIFN7 L. lactis strains were analysed. Control samples (no MitC) indicated by dashed bars; mitomycin $C$ treated samples (+MitC) indicated by filled bars. The quantification is based on quantification of phage DNA by agarose gel electrophoresis

GFP-labelled WT much faster than the controls, whereas mCherry-labelled WT cells were relatively more competitive with the GFP-labelled cured strain. These data show that even under optimal growth conditions the prophage bearing wild type TIFN1 cells have a competitive advantage compared to their cured derivatives. Figure 9b shows the dot plots obtained for two exemplary experimental samples recorded after 2 days of propagation in mixed culture.

The same mixed cultures were diluted and plated after 2 days of propagation and the ratio between GFP and mCherry expressing cells were analysed by fluorescent colony count. The results corresponded to the results obtained by flow cytometry. On day 2 the GFP/mCherry expressing cells were $\sim 85 \% / 15 \%$ in both WT and both cured strains, $97 \% / 3 \%$ in GFP-WT \& mCherry-cured culture and $62 \% / 38 \%$ in the combination of GFP-cured \& mCherry-WT.

Table 3 Comparative effect of the environmental stress and standard growth conditions on spontaneous prophage induction

\begin{tabular}{llllll}
\hline phage & MitC & 0.4-fold LM17 & $34{ }^{\circ} \mathrm{C}$ & $1 \% \mathrm{NaCl}$ & $2 \% \mathrm{NaCl}$ \\
\hline proФ1 & + & & + & & \\
$\operatorname{proФ2~}$ & + & - & + & & \\
$\operatorname{proФ3}$ & + & & & + & + \\
$\operatorname{proФ4}$ & + & - & + & & \\
$\operatorname{proФ5}$ & + & - & + & & + \\
$\operatorname{proФ6}$ & + & $\mathrm{ND}$ & & + & + \\
$\operatorname{proФ7}$ & + & & + & &
\end{tabular}

The table summarises data shown in Additional file 3 and Additional file 4. (+) stress induction > standard induction; $(-)$ stress induction < standard induction; (empty cell) not significant differences; (ND) not determined. MitC induction $(0.3 \mu \mathrm{g} / \mathrm{ml})$ was used as positive control
A growth experiment with a mixed culture was also performed with mCherry labelled strain TIFN2 and its GFP labelled derivative strain TI2c. The ratio of GFP and mCherry cells was monitored by flow cytometry during $5 \mathrm{~h}$ (Fig. 9e). A similar trend of wild type persistence in the culture compared to its prophage cured derivative was observed.

\section{Discussion}

In the current study we investigated the presence, identity, behaviour, and impact on host competitive power of prophages in L. lactis strains isolated from a complex starter culture (Ur), used for industrial cheese production. All lactococcal strains analysed were found to be lysogenic. Remarkably, the prophages were found to be excised from the bacterial chromosome, replicated, packaged, and finally released from the cells in substantial amounts, both in the absence and presence of a prophage inducing drug (mitomycin $\mathrm{C}$ ), although no tailed viral particles were detected in any of the supernatants from induced cultures. Earlier studies reported up to $10^{4}$ [35] and $10^{6}$ [36] plaque forming units per $\mathrm{ml}$ were present in supernatants of lactococcal cultures due to spontaneous induction. Our results implicate that between $10^{8}$ and $10^{9}$ (pro) phage particles per $\mathrm{ml}$ culture of the lysogenic strains are permanent residents of the microbial community of the starter culture, a number that is expected to increase further if the culture is subjected to environmental stress conditions such as elevated temperature or increased salinity. The latter conditions are encountered during cheese making. Some studies performed in factories where L. lactis is used as starter culture, reported up to $10^{9}$ phages per $\mathrm{ml}$ of whey e.g. [37] but this was regarded as a detrimental phage contamination. Interestingly, continuous or even induced release of prophages does not seem to result in massive cell lysis, not in the pure cultures of the isolates and also not in the complex starter [20].

The question now arises how the maintenance of lysogeny, and more particular the observed continuous release of phage crop, relates to the evolutionary success of the native strains in the undefined starter culture. Moreover, it should be noted that the abundantly released phage particles are tailless which may suggest they are incomplete or defective. Production of phage particles is an energetically expensive process as metabolic energy is required for the replication of the viral DNA and assembly of the virions. The process of phage DNA packaging is driven by a molecular motor that utilizes energy derived from ATP hydrolysis, as reviewed in [38]. For example, the force involved in the DNA compaction process for filling a phage capsid can be converted into an intra-capsid pressure as large as $60 \mathrm{~atm}$ at the expense of ATP hydrolysis [39]. It has been shown 


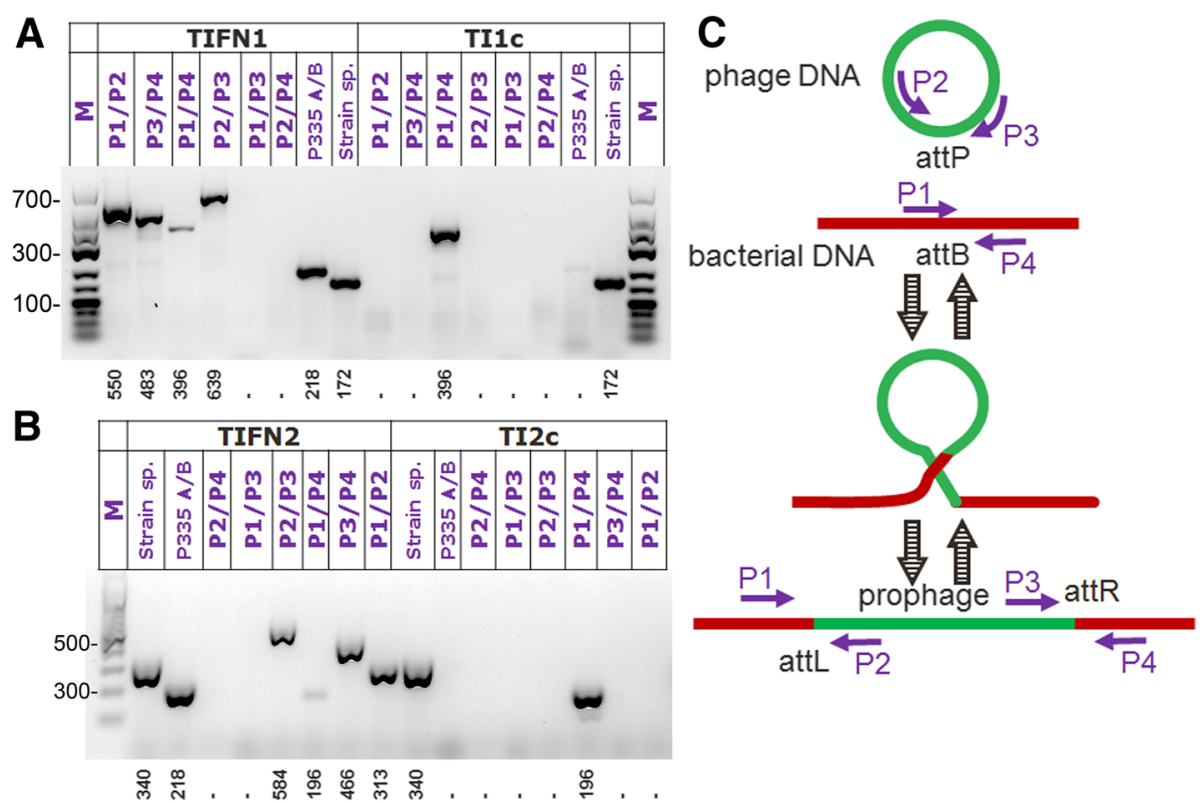

Fig. 8 PCR analysis of prophage excision and integration. Panel a shows the analysis of L. lactis TIFN1 and its cured derivative TI1C. Panel $\mathbf{b}$ shows the analysis of L. lactis TIFN2 and its cured derivative TI2c. The combination of primers are indicated above each lane, expected amplicon size is depicted beneath each lane in panels $\mathbf{a}$ and (b), (c). Schematic representation of the PCR analysis strategy showing primer binding sites (not to scale)

for $\Phi 29$ and T3 bacteriophages that 2 bp are packaged per ATP molecule cleaved by the motors [40, 41]. Despite this huge metabolic burden associated with the continuous release of phage particles, lysogens are obviously competitive in the community as initially evidenced by their high relative abundance in the culture and also confirmed in competition experiments between wild types and their prophage-cured derivatives. In mixed cultures the wild type lysogens outgrow the cured competitor, however, our experiments cannot discriminate between true increased fitness of the wild type strain from a detrimental effect of released phage particles on the cured competitor strain.

Although the phenomenon of spontaneous prophage induction (i.e. prophage induction under non-inducing conditions) in a microbial population has been described in the early 50s of the twentieth century [42] it regained attention in the recent years $[43,44]$. Spontaneous induction is usually linked to the activity of an SOS response system, common in bacteria [45]. It is therefore not surprizing that for some strains we observed increased spontaneous induction in cultures challenged by stress conditions such as elevated temperature and osmotic upshift. In contrast, low nutrient concentrations can stabilize lysogeny [46] which also agrees with our observations that induction frequency in some cases declined. Remarkably, other authors have also observed enhanced induction of temperate lactococcal bacteriophage
phiLC3 by environmental stimuli [47]. The authors found significant increase in induction frequency at elevated temperatures $\left(34.5^{\circ} \mathrm{C}\right)$, which is in agreement with our observations. However, under the conditions of nutrients depletion (0.4-fold LM17) the authors observed an increase in phiLC3 induction as well, whereas elevated $\mathrm{NaCl}$ concentration (1.5\%) had an opposite effect. This discrepancy indicates that the environmental stresses triggering prophage induction are phage or strain specific. It has also been observed earlier, for example, that prophages of the polylysogenic Enterococcus faecalis strain V583 responded differently to environmental challenges [48].

Spontaneous prophage activity has been studied also in models for biofilm formation, and pathogenesis of human diseases and it has been shown to lead to competitive advantages and benefits for the bacterial populations by enhancing biofilm formation, playing a vital role in bacterial virulence or leading to horizontal gene transfer $[43,49]$.

Our findings open new perspectives in understanding population biology and evolution of complex mixed microbial communities. Despite a huge metabolic burden imposed on cells due to continuous production and release of phage particles, the evolutionary success of these lysogens is evident from their high abundance in the culture. However, the most interesting question about the mechanisms by which the tailless (pro) phages provide 

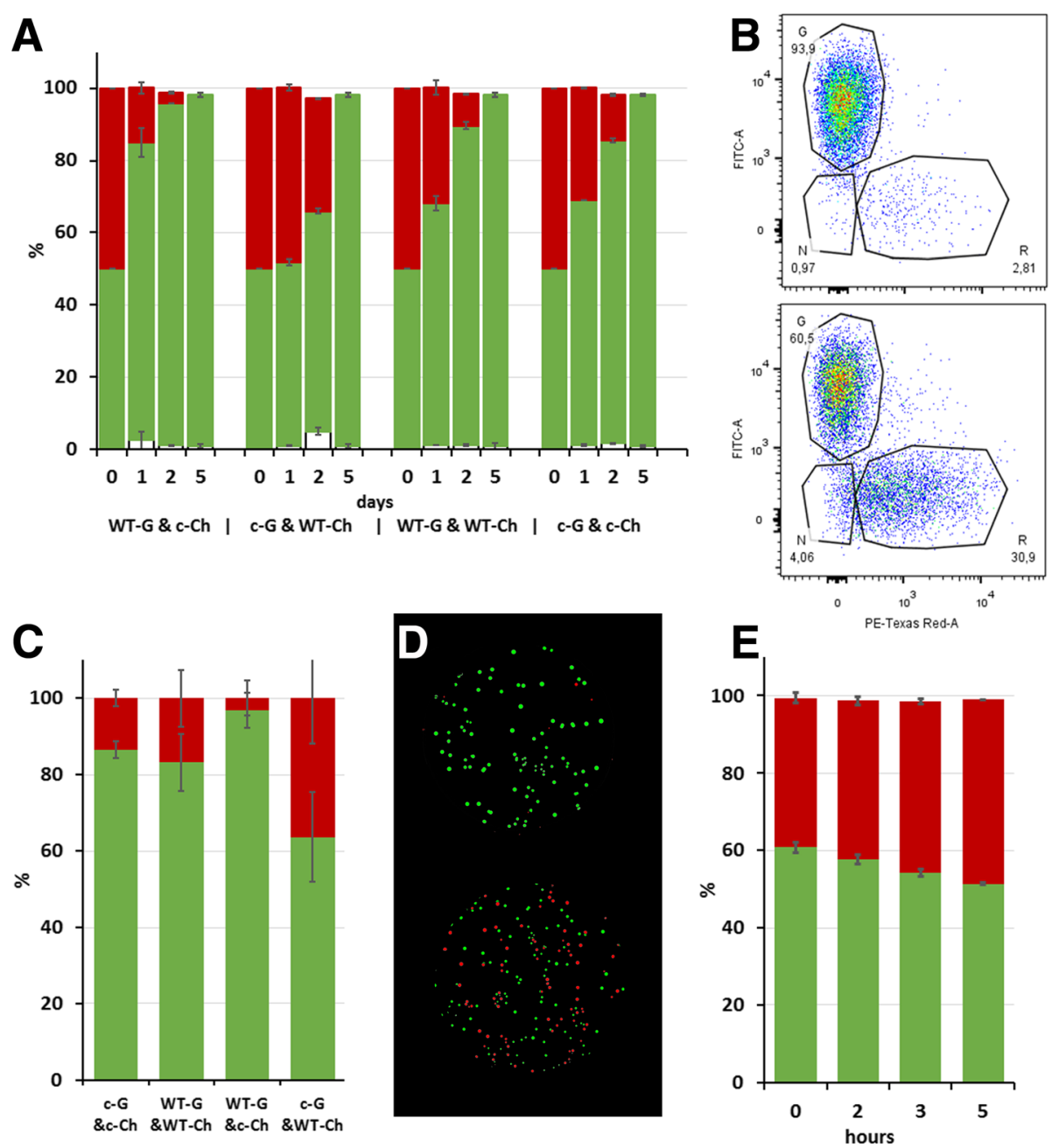

Fig. 9 Competition between labelled wild-type and their prophage-cured derivative strains. a Ratio between labelled TIFN1 and TI1c cells propagated in mixed cultures in four different combinations and monitored by flow cytometry during 5 days. Green bars - GFP, red bars - mCherry, WT - wild type, c - cured derivative, G - GFP, Ch - mCherry. b Exemplary dot plots of experimental specimens shown in panel a recorded on propagation day 2 with encompassing gates for cell population expressing GFP-G, mCherry-R, negative cells-N and corresponding statistics; GFP-WT \& mCherry-cured (upper panel) and GFP-cured \& mCherry-WT (lower panel). On the $y$-axis is the GFP fluorescence intensity, on the x-axis - mCherry fluorescence intensity (log-scales). c Ratio between the GFP and mCherry expressing TIFN1 and TI1c cells after 2 days of propagation in mixed cultures as revealed by fluorescent colony count. $\mathbf{d}$ Exemplary images (overlay, pseudo colour) of the experimental specimens shown in panel c. GFP-WT \& mCherry-cured (upper panel) and GFP-cured \& mCherry-WT (lower panel). e Ratio between GFP-TI2C and mCherry-TIFN2 grown in mixed culture monitored by flow cytometry during $5 \mathrm{~h}$

their hosts with a competitive advantage remains to be answered. Furthermore, our findings suggest that the presence of prophages and their release plays an important role in the ecosystem.

\section{Conclusions}

The results of this study indicate that chromosomal genetic elements are active participants in the stable complex microbial community, shaped by the natural evolution (and natural selection). We show that prophages are abundant in such a community, produced continuously in large amounts and, despite the huge metabolic burden imposed on the cells by phage particle production, provide a selective advantage to the host.

\section{Additional files}

Additional file 1: Figure S1. Phage genome size estimation using conventional long run and field inversion (FIGE) agarose gel electrophoresis. A. proФ1 (lane 4, non-induced, $R f=0.167,40.7 \mathrm{kbp}$ ), pro $\Phi 1$ (lane 5, MitC induced, $\mathrm{Rf}=0.167,40.7 \mathrm{kbp}$ ) and pro $\$ 2$ (MitC induced, $\mathrm{Rf}=0.173,39.5 \mathrm{kbp}$ ) genomic DNA resolved using long run conventional electrophoresis. B. proФ1 $(\mathrm{Rf}=0.102,40.7 \mathrm{kbp})$ and pro $\Phi 5(\mathrm{Rf}=0.102,40.7 \mathrm{kbp})$ genomic DNA resolved using FIGE. The $\lambda$ genome (last lane) size, determined in the analysis 
is $48.3 \mathrm{kbp}(\mathrm{Rf}=0.089)$, which is close to its actual size $48.5 \mathrm{kbp}$. C and $\mathrm{D}$ show calibration curves for $A$ and $B$ respectively. The size of the marker fragments (Thermo Scientific, in base pairs) are: $\lambda$ mix 19-48,502, 38,416, $33,498,29,946,24,508,23,994,19,397,17,053,15,004,12,220,10,086,8614$, 8271; High Range (HR) - 48,502, 24,508, 20,555, 17,000, 15,258, 13,825, 12,119, 10,171. (TIF $5860 \mathrm{~kb}$ )

Additional file 2: Figure S2. Phage DNA in supernatants of Mitomycin $C$ induced 14 strains of TIFN1 and TIFN5 lineages visualized on agarose gel electrophoresis. High range ladder ( $\mathrm{HR}, 48-10 \mathrm{kbp}$ ) and different $\lambda$ DNA concentrations are used as markers for molecular weight and phage release estimation. The lower molecular weight species on the bottom of the gel in Figure S2 are presumably rRNA. Such bands, found in all phage preparations, correspond to $\sim 1100$ and $\sim 900$ base pair (DNA size), degraded by Benzonase ${ }^{\ominus}$ Nuclease but not by DNAse, and prone to degradation in time (not shown). (TIF $3020 \mathrm{~kb}$ )

Additional file 3: Figure S3. Spontaneous prophage induction in cultures of 7 TIFN strains subjected to stress conditions based on quantification of phage DNA by agarose gel electrophoresis. MitC driven induction and induction without any stress applied (NC) were also analysed in the series of experiments for comparison. (TIF $3302 \mathrm{~kb}$ )

Additional file 4: Figure S4. Comparison of prophage yield under stress growth and standard growth conditions. Filled bars indicate statistically significant difference in prophage induction. We allowed the confidence interval 90\%, $p<0.1$ (unpaired double-sided t-test versus negative control) to consider the difference significant because of significant impact of even small difference in induction conditions on amount of phages released as exemplified in Fig. 4. (TIF $1405 \mathrm{~kb}$ )

\section{Abbreviations}

FIGE: Field-inversion gel electrophoresis; FSC: Forward-scattered light GAC: Glycine adapted cells; GFP: Green fluorescent protein; LAB: Lactic acid bacteria; LM17: M17 medium, supplemented with 0.5\% lactose; MitC: Mitomycin C; $\mathrm{OD}_{600}$ : Culture turbidity, optical density at $600 \mathrm{~nm}$; PEG: Polyethylene glycol; PHAST: Phage Search Tool; SSC: Side-scattered light; TEM: Transmission electron microscopy; WT: Wild type

\section{Acknowledgments}

The authors gratefully acknowledge Jan van Lent (Wageningen Electron Microscopy Center (WEMC)) for his help with Electron Microscopy. Furthermore we thank the master students Yixin Ge, Ilias Theodorou, Joanna Kaczorowska, Laura Melissant, the students of Advanced Fermentation Science courses (FHM 30806-2013-2014) and the honours students Pippi-Lotte Maessen, Jildou Smit and Joep Spaen, for their contribution to the project. Finally, we would also like to thank Prof. J. Kok, University of Groningen The Netherlands for providing the plasmids pSEUDO-GFP and pIL253.

\section{Funding}

The project is funded by TI Food and Nutrition, a public-private partnership on precompetitive research in food and nutrition under grant FF01. The public partners are responsible for the study design, data collection and analysis, decision to publish, and preparation of the manuscript. The private partners have contributed to the project through regular discussion.

\section{Availability of data and materials}

All data generated or analysed during this study are included in this published article and its supplementary information files.

\section{Authors' contributions}

SA and EJS made substantial contributions to conception and design of the study. SA, JAGM and MS were involved in data acquisition and data analysis. SA, and EJS were involved in interpretation of data, drafting the manuscript and revising it critically for important intellectual content. All authors read and approved the final manuscript.

\section{Ethics approval and consent to participate}

Not applicable.

\section{Consent for publication}

Not applicable.

\section{Competing interests}

The authors declare that they have no competing interests.

\section{Publisher's Note}

Springer Nature remains neutral with regard to jurisdictional claims in published maps and institutional affiliations.

Received: 20 June 2017 Accepted: 9 August 2018

Published online: 24 September 2018

\section{References}

1. Smid EJ, Erkus O, Spus M, Wolkers-Rooijackers JC, Alexeeva S, Kleerebezem M Functional implications of the microbial community structure of undefined mesophilic starter cultures. Microbial Cell Fact. 2014;13 Suppl 1:S2.

2. Erkus O, de Jager VC, Spus M, van Alen-Boerrigter IJ, van Rijswijck IM, Hazelwood L, Janssen PW, van Hijum SA, Kleerebezem M, Smid EJ. Multifactorial diversity sustains microbial community stability. ISME J. 2013;4(10):108.

3. Huggins AR, Sandine WE. Incidence and properties of temperate bacteriophages induced from lactic streptococci. Appl Environ Microbiol. 1977;33(1):184-91

4. Terzaghi BE, Sandine WE. Bacteriophage production following exposure of lactic streptococci to ultraviolet radiation. J Gen Microbiol. 1981;122(2):305-11.

5. Davidson BE, Powell IB, Hillier AJ. Temperate bacteriophages and lysogeny in lactic acid bacteria. FEMS Microbiol Rev. 1990;7(1-2):79-90.

6. Bolotin A, Wincker P, Mauger S, Jaillon O, Malarme K, Weissenbach J, Ehrlich $\mathrm{SD}$, Sorokin A. The complete genome sequence of the lactic acid bacterium Lactococcus lactis ssp. lactis IL1403. Genome Res. 2001;11(5):731-53.

7. Ventura M, Zomer A, Canchaya C, O'Connell-Motherway M, Kuipers O, Turroni F, Ribbera A, Foroni E, Buist G, Wegmann U, et al. Comparative analyses of prophage-like elements present in two Lactococcus lactis strains. Appl Environ Microbiol. 2007;73(23):7771-80

8. Chopin A, Bolotin A, Sorokin A, Ehrlich SD, Chopin M. Analysis of six prophages in Lactococcus lactis IL1403: different genetic structure of temperate and virulent phage populations. Nucleic Acids Res. 2001:29(3):644-51.

9. Desiere F, Lucchini S, Canchaya C, Ventura M, Brussow H. Comparative genomics of phages and prophages in lactic acid bacteria. Antonie Van Leeuwenhoek. 2002;82(1-4):73-91.

10. Moineau S, Pandian S, Klaenhammer TR. Evolution of a lytic bacteriophage via DNA acquisition from the Lactococcus lactis chromosome. Appl Environ Microbiol. 1994;60(6):1832-41.

11. Casjens S. Prophages and bacterial genomics: what have we learned so far? Mol Microbiol. 2003:49(2):277-300.

12. Garneau JE, Moineau S. Bacteriophages of lactic acid bacteria and their impact on milk fermentations. Microbial Cell Fact. 2011;10 Suppl 1:S20.

13. Maniloff J, Cadden SP, Putzrath RM. Maturation of an enveloped budding phage: mycoplasmavirus L2. Prog Clin Biol Res. 1981;64:503-13.

14. Edlin $G$, Lin LEO, Kudrna R. $\lambda$ Lysogens of $E$. coli reproduce more rapidly than non-lysogens. Nature. 1975;255(5511):735-7.

15. Edlin G, Lin L, Bitner R. Reproductive fitness of P1, P2, and mu lysogens of Escherichia coli. J Virol. 1977;21(2):560-4.

16. Casjens SR. Comparative genomics and evolution of the tailedbacteriophages. Curr Opin Microbiol. 2005:8(4):451-8.

17. Bondy-Denomy J, Davidson A. When a virus is not a parasite: the beneficial effects of prophages on bacterial fitness. J Microbiol. 2014;52(3):235-42.

18. Ohnishi M, Kurokawa K, Hayashi T. Diversification of Escherichia coli genomes: are bacteriophages the major contributors? Trends Microbiol. 2001;9(10):481-5.

19. Casjens S, Hendrix R. Bacteriophages and the bacterial genome. In: Higgins NP, editor. The bacterial chromosome. Washington: ASM Press; 2003. p. 39-52.

20. Spus M, Li M, Alexeeva S, Wolkers-Rooijackers J, Zwietering M, Abee T, Smid E. Strain diversity and phage resistance in complex dairy starter cultures. J Dairy Sci. 2015;98:5173-82

21. Zhou Y, Liang Y, Lynch KH, Dennis JJ, Wishart DS. PHAST: a fast phage search tool. Nucleic Acids Res. 2011;39(Web Server issue):14.

22. Raya RR, Hebert EM. Isolation of phage via induction of lysogens. In: Clokie MRJ, Kropinski AM, editors. Bacteriophages: Methods and Protocols. New York: Humana Press. 2009; p. 23-32.

23. Branston S, Stanley E, Keshavarz-Moore E, Ward J. Precipitation of filamentous bacteriophages for their selective recovery in primary purification. Biotechnol Prog. 2012;28(1):129-36. 
24. Ly-Chatain MH, Durand L, Rigobello V, Vera A, Demarigny Y. Direct quantitative detection and identification of Lactococcal bacteriophages from milk and whey by real-time PCR: application for the detection of Lactococcal bacteriophages in Goat's raw milk whey in France. Int J Microbiol. 2011;2011:594369.

25. Jensen PR, Hammer K. The sequence of spacers between the consensus sequences modulates the strength of prokaryotic promoters. Appl Environ Microbiol. 1998;64(1):82-7.

26. Pinto JP, Zeyniyev A, Karsens H, Trip H, Lolkema JS, Kuipers OP, Kok J. pSEUDO, a genetic integration standard for Lactococcus lactis. Appl Environ Microbiol. 2011;77(18):6687-90.

27. Pedelacq JD, Cabantous S, Tran T, Terwilliger TC, Waldo GS. Engineering and characterization of a superfolder green fluorescent protein. Nat Biotechnol. 2006;24(1):79-88.

28. Simon D, Chopin A. Construction of a vector plasmid family and its use for molecular cloning in Streptococcus lactis. Biochimie. 1988;70(4):559-66.

29. Alexeeva S, Gadella TW, Verheul J, Verhoeven GS, Den Blaauwen T. Direct interactions of early and late assembling division proteins in Escherichia coli cells resolved by FRET. Mol Microbiol. 2010;77(2):384-98.

30. Holo H, Nes IF. High-frequency transformation, by electroporation, of Lactococcus-Lactis Subsp Cremoris grown with Glycine in osmotically stabilized media. Appl Environ Microb. 1989;55(12):3119-23.

31. Wegmann U, O'Connell-Motherway M, Zomer A, Buist G, Shearman C, Canchaya C, Ventura M, Goesmann A, Gasson MJ, Kuipers OP, et al. Complete genome sequence of the prototype lactic acid bacterium Lactococcus lactis subsp. cremoris MG1363. J Bacteriol. 2007;189(8):3256-70.

32. Mahony J, Martel B, Tremblay DM, Neve H, Heller KJ, Moineau S, van Sinderen D. Identification of a new P335 subgroup through molecular analysis of lactococcal phages Q33 and BM13. Appl Environ Microbiol. 2013:79(14):4401-9.

33. de Vos WM, Davies FL.Plasmid DNA in lactic streptococci: bacteriophage resistance and proteinase plasmids in Streptococcus cremoris SK11. In: Third European Congress on Biotechnology, vol. 3. Munich, Verlag Chemie. 1984; 201-206

34. Lunde M, Blatny JM, Lillehaug D, Aastveit AH, Nes IF. Use of real-time quantitative PCR for the analysis of phiLC3 prophage stability in lactococci. Appl Environ Microbiol. 2003;69(1):41-8.

35. Cuesta P, Suarez JE, Rodriguez A. Incidence of Lysogeny in wild Lactococcal strains. J Dairy Sci. 1995;78(5):998-1003.

36. Reyrolle J, Chopin M, Letellier F, Novel G. Lysogenic strains of lactic acid streptococci and lytic spectra of their temperate bacteriophages. Appl Environ Microbiol. 1982;43(2):349-56.

37. Neve H, Kemper U, Geis A, Heller KJ. Monitoring and characterization of lactococcal bacteriophage in a dairy plant. Kiel Milchwirtsch Forschungsber. 1994:46:167-78.

38. Casjens SR. The DNA-packaging nanomotor of tailed bacteriophages. Nat Rev Microbiol. 2011;9(9):647-57.

39. Chemla YR, Aathavan K, Michaelis J, Grimes S, Jardine PJ, Anderson DL, Bustamante C. Mechanism of force generation of a viral DNA packaging motor. Cell. 2005;122(5):683-92.

40. Guo P, Peterson C, Anderson D. Prohead and DNA-gp3-dependent ATPase activity of the DNA packaging protein gp16 of bacteriophage phi 29. J Mol Biol. 1987;197(2):229-36.

41. Morita M, Tasaka M, Fujisawa H. DNA packaging ATPase of bacteriophage T3. Virology. 1993;193(2):748-52.

42. Lwoff A. Lysogeny. Bacteriol Rev. 1953;17(4):269-337.

43. Carrolo M, Frias MJ, Pinto FR, Melo-Cristino J, Ramirez M. Prophage spontaneous activation promotes DNA release enhancing biofilm formation in Streptococcus pneumoniae. PLoS One. 2010:5(12):e15678.

44. Nanda AM, Heyer A, Kramer C, Grunberger A, Kohlheyer D, Frunzke J. Analysis of SOS-induced spontaneous prophage induction in Corynebacterium glutamicum at the single-cell level. J Bacteriol. 2014;196(1):180-8.

45. Little JW. Chance phenotypic variation. Trends Biochem Sci. 1990;15(4):138.

46. Guttman B, Raya R, Kutter E. Basic phage biology. In: Kutter E, Sulakvelidze A, editors. Bacteriophages: Biology and Applications. FL: CRP Press; 2005. p. 29-66

47. Lunde M, Aastveit AH, Blatny JM, Nes IF. Effects of diverse environmental conditions on \{phi\}LC3 prophage stability in Lactococcus lactis. Appl Environ Microbiol. 2005;71(2):721-7
48. Matos RC, Lapaque N, Rigottier-Gois L, Debarbieux L, Meylheuc T, GonzalezZorn B, Repoila F, de Fatima LM, Serror P. Enterococcus faecalis prophage dynamics and contributions to pathogenic traits. PLoS Genet. 2013;9(6):e1003539.

49. Nanda AM, Thormann K, Frunzke J. Impact of spontaneous prophage induction on the fitness of bacterial populations and host-microbe interactions. J Bacteriol. 2015;197(3):410-9.
Ready to submit your research? Choose BMC and benefit from:

- fast, convenient online submission

- thorough peer review by experienced researchers in your field

- rapid publication on acceptance

- support for research data, including large and complex data types

- gold Open Access which fosters wider collaboration and increased citations

- maximum visibility for your research: over $100 \mathrm{M}$ website views per year

At $\mathrm{BMC}$, research is always in progress.

Learn more biomedcentral.com/submissions 